ISSN: 2238-8052

Volume 7, Número 1 (2018)

Movimentos Sociais \&

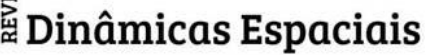

\title{
TERRITÓRIOS AMEAÇADOS NO CONTEXTO DE EXPANSÃO DA URBANIZAÇÃO NEOLIBERAL - O CASO DO COQUE - RECIFE - PE
}

\author{
THREATENED TERRITORIES IN THE CONTEXT OF EXPANSION OF NEOLIBERAL \\ URBANIZATION - THE CASE OF COQUE-RECIFE-PE
}

\author{
Cláudio Jorge Moura de CASTILHO ${ }^{1}$ \\ Diana Carolina Gómez BAUTISTA2 \\ Dóris Jamylla Siqueira Lopes CAMPOS 3 \\ Milena Barros GOMES 4
}

Artigo recebido em 11/02/2018 e aceito em 02/07/2018

Palavras-chave:

Territórios vividos; Especulação imobiliária;

Coque.
Keywords: Lived Territories; Real Estate Speculation; Coque.

\section{R E S U M O}

No curso da história urbana em Recife, os territórios vividos resistem contra a especulação imobiliária cujos interesses fizeram parte preponderante, desde muito cedo, da formação da cidade. Pretende-se contribuir para a discussão sobre o atual processo de urbanização capitalista que tem ameaçado territórios historicamente conquistados pelas populações pobres. Partindo de uma experiência de resistência do território Coque, o grupo de pesquisa MSEU identificou o retorno de maneira célere da postura urbanística higienista em Recife. Como procedimentos metodológicos, utilizou-se de uma abordagem relacional mediante a qual a interdisciplinaridade é considerada como caminho fundamental à apreensão e explicação da complexidade do processo de urbanização sob o capitalismo.

\begin{abstract}
A B S T R A C T
During the urban history in Recife, lived territories resist against real estate speculation whose interests have been become the most important during the entire process of city formation. This article contributes to the discussion of the current capitalist urbanization process which threatens territories historically constructed by the poor populations. Starting from experiences in the Coque territory, the research group MSEU) identified the return of the hygienist urban publicy action in Recife. As methodological procedures, we used a relational approach by which interdisciplinarity is considered as a fundamental way to understand the problem and to explain the complexity of the capitalist urbanization.
\end{abstract}

\footnotetext{
1 Professor Associado do Departamento de Ciências Geográficas da Universidade Federal de Pernambuco, Coordenador do Grupo de Pesquisa Movimentos Sociais e Espaço Urbano, Bolsista de produtividade nível 1D do CNPq. E-mail: claudiocastilho44@gmail.com.

2 Assistente Social e doutoranda do Programa de Pós-graduação em Desenvolvimento e Meio Ambiente da Universidade Federal de Pernambuco - PRODEMA/UFPE, bolsita FACEPE e Membro do Grupo de pesquisa Movimentos Sociais e Espaço Urbano - MSEU. E-mail: dianacaro.gomez@gmail.com.

3 Geógrafa e Mestra em Desenvolvimento Urbano - MDU|UFPE. Docente do curso de Arquitetura e Urbanismo dos Centros Universitários UNIFBV|WYDEN e UNIFAVIP|WYDEN. E-mail: dorisjslcampos@gmail.com.

${ }^{4}$ Licenciada em Geografia pela UFPE, professora do Colégio 2001. E-mail: milenabarrosgomes@gmail.com.
} 


\section{CONSIDERAÇÕES INICIAIS}

Parte-se do pressuposto de que a teoria social crítica sobre o processo de urbanização no mundo moderno tem demonstrado que, no contexto do sistema capitalista, o espaço urbano tem sido produzido (HARVEY, 2004, 2005, 2010; LEFEBVRE, 1999a, 1999b), predominantemente, para garantir os interesses, articulados em torno do Complexo Fundiário Imobiliário Comercial Financeiro (CFICF), fundamentais à acumulação de capital, sobretudo no contexto da racionalidade técnico-instrumental capitalista.

The production of space in general and of urbanisation in particular has bocome big business under capitalism. It is one of the key ways in which the capital surplus is absorbed. [...] The connections between urbanisation, capital accumulation and crisis formation desserve careful scrutiny. (HARVEY, 2010, p.166)

Desse modo, tratando-se da produção de territórios sob os parâmetros da lógica da racionalidade técnico-instrumental capitalista, hoje com tendência explicitamente neoliberal, desconsidera-se os interesses inerentes às classes subalternas e oprimidas, isto é, aquelas que vivem do trabalho.

Durante a história do processo de urbanização em Recife (Brasil) - cidade que nunca deixou de manter, em sua paisagem, as características perversas inerentes à formação territorial do capitalismo no Brasil - vale ressaltar que os interesses da acumulação de capital quase sempre conseguiram sobrepor-se sobre os interesses da realização plena da vida humana (CASTILHO, 2011).

Com isto, produziram-se territórios para servirem de base para a acumulação de capital puramente econômico, mesmo que negando e destruindo os territórios pertencentes às classes sociais subalternas e oprimidas. Esclarece-se que se considera, neste artigo, o território como espaço resultante

[...] d'une action conduite par un acteur syntagmatique (acteur réalisant un programme) à quelque niveau que ce soit. En s'appropriant concrètement ou abstraitement (par exemple, par la représentation) un espace, l'acteur 'territorialise' l'espace. [...] Le territoire, dans cette perspective, est un espace dans lequel on a projété du travail, soit de l'énergie et de l'information, et qui, par conséquent, révèle des relations toutes marquées par le pouvoir. L'espace est la 'prison originelle', le territoire est la prison que les hommes se donnent. (RAFFESTIN, 1980, p.129)

Como "prisão criada pelos homens", o território é o espaço onde o trabalho se projeta, é vida. Portanto, quando se retira o território das pessoas que os produziram, elas também perdem suas formas de existência, problema que se agrava quando não se lhes oferecem alternativas concretas de vida digna na cidade. Os territórios que se localizam no caminho da expansão permanente dos interesses do CFICF estão sendo ameaçados de desaparecerem enquanto territorialidades ${ }^{5}$ das classes subalternas e oprimidas, ou seja, aquelas que não interessam à racionalidade vigente.

\footnotetext{
5 Procedendo de uma "problemática relacional", a territorialidade inscreve-se "[...] dans le cadre de la production, de l'échange et de la consommation des choses. [...] C'est toujours un rapport, même s'il est différé, avec les autres acteurs.
} 
Com relação ao anteriormente colocado, através da reflexão e argumentação realizadas por Rolnik (2015) acerca da colonização da terra e da moradia na cidade na era das finanças, pode-se chegar à conclusão de que, para atender seus propósitos, os interesses hegemônicos estão desrespeitando leis urbanísticas instituídas para garantir a manutenção das territorialidades, hoje ameaçadas, das classes subalternas e oprimidas. 0 que está sendo reforçado por práticas urbanísticas higienistas que estimulam processos de gentrificação do espaço. 0 que se torna ainda mais perverso em cidades localizadas em regiões de países "subdesenvolvidos".

Tanto que mesmo leis (como a da institucionalização das Zonas Especiais de Interesse Social Zeis) e instrumentos urbanísticos (Plano de Regularização das Zonas Especiais de Interesse Social Prezeis), socialmente construídos, acham-se hoje ameaçados. As Zeis, por exemplo, instituídas nos anos oitenta do século XX, visam garantir o direito das classes subalternas e oprimidas de permanecerem nos territórios ocupados e produzidos por elas mesmas no curso da sua história de vida na cidade. Em princípio, elas são “[...] assentamentos habitacionais populares, surgidos espontaneamente a partir de ocupações em áreas públicas e privadas, não dispondo de infraestrutura básica de urbanização e sem ter a sua situação fundiária regularizada". (CENDHEC, 1997, p.6).

No que diz respeito ao Coque, localizado em Recife (Fig.1), este é um dos territórios que, historicamente produzido pelos seus próprios moradores, também vem sendo, paulatinamente, ameaçado pelos interesses da lógica da racionalidade técnico-instrumental do capitalismo neoliberal, pela qual se deseja conquistá-lo a fim de produzi-lo de acordo com os interesses da expansão de ações puramente especulativas. Desse modo, mesmo sendo, desde 1983, uma Zeis, o território Coque vem sendo, constantemente, ameaçado pelos interesses ligados ao CFICF.

Vale ressaltar que, uma vez que o Coque constitui um território historicamente ocupado, produzido e vivido, possuindo significativas territorialidades, ele também pode ser considerado como uma rugosidade, ou seja, como um conjunto complexo de "heranças físico-territoriais, mas também [...] heranças socioterritoriais ou sociogeográficas" (SANTOS, 1997, p.36) com potencial para influir no tempo presente a exemplo das suas experiências de mobilização social, valores de solidariedade e autonomia. Como tal, não é e não será fácil apagar territórios como este, sobretudo se houver movimentos de oposição ao projeto de cidade neoliberal, os quais, inclusive, acontecem hoje, também por meio do uso das diversas redes sociais e informacionais.

\footnotetext{
Toutes production du système territorial determine ou conditionne une consommation de celui-ci. [...] La territorialité se manifèste à toutes les échelles spatiales et sociales, elle est consubstantielle de tous les rapports et on pourrait dire qu' elle est en quelque sorte la 'face vécue' de la 'face agie' du pouvoir". (RAFFESTIN, 1980, p. 146)
} 
Figura 1. Localização da Zeis Coque na cidade do Recife.

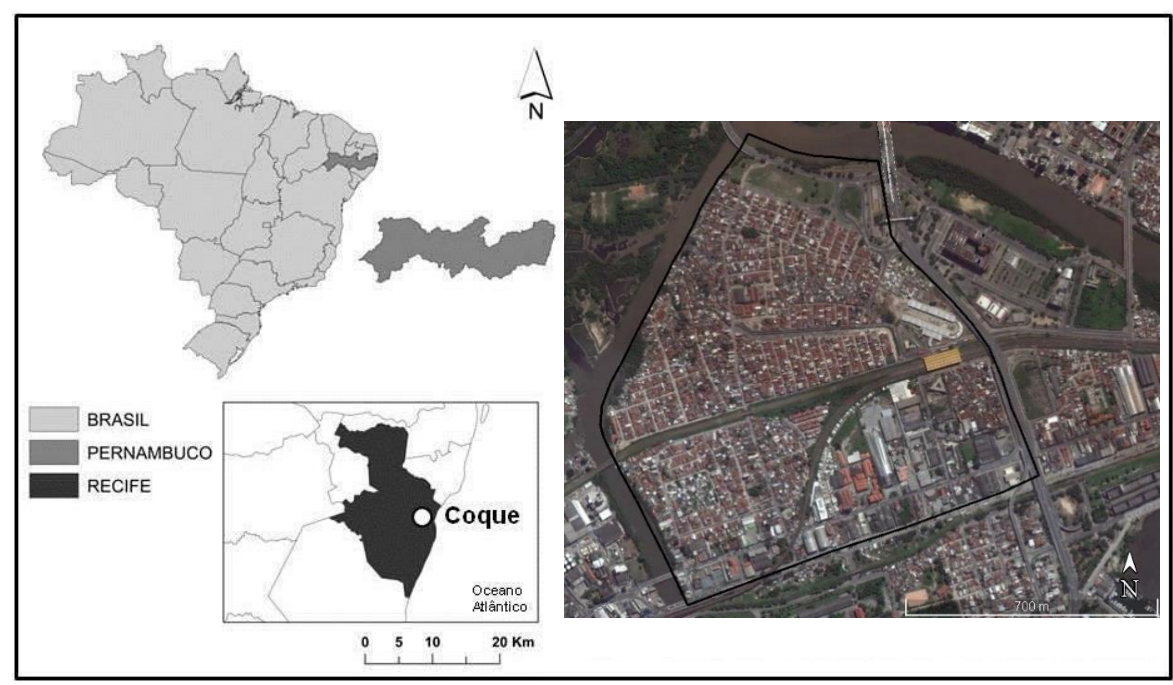

Fonte da imagem: Google Earth Pro, 2016.

Em face do exposto, o presente artigo pretende contribuir para a discussão, recentemente retomada no Brasil, sobre o papel do atual processo de urbanização capitalista que vem ameaçando territórios historicamente produzidos por pessoas oriundas das classes sociais subalternas e oprimidas. 0 que será realizado a partir da apresentação, para reflexão, de uma experiência que aconteceu em Recife, no âmbito do retorno, de maneira mais intensa e célere, da postura urbanística higienista norteada pela lógica técnico-instrumental capitalista neoliberal, a qual, através do CFICF, insiste em continuar interferindo no processo de produção do espaço das nossas cidades como uma grande empresa.

\section{METODOLOGIA}

O grupo de pesquisa Movimentos Sociais e Espaço Urbano (MSEU), no âmbito da participação de uma equipe interdisciplinar de pesquisadores e estudantes de graduação e pós-graduação, procura entender as dinâmicas dos movimentos sociais, a geograficidade de suas práticas e o complexo mosaico do espaço, através da promoção de discussões e debates, tentando ultrapassar a lógica da racionalidade técnico-instrumental vigente e, ao mesmo tempo, pensando na possibilidade de se construir uma outra lógica de produção dos nossos espaços.

Optou-se, portanto, mais uma vez, pela abordagem relacional mediante a qual a interdisciplinaridade é considerada como caminho fundamental à apreensão, ao entendimento e à explicação do processo de urbanização capitalista como uma totalidade complexa tecida pelas interrelações entre as dimensões materiais e imateriais da realidade urbana.

A la problématique morpho-fonctionnelle, il faut sinon substituer, du moins ajouter une problématique relationnelle dont les résultats, s'il y en a, seront connotatifs de ceux issus de la première. [...] En fait, il n'en est rien puisque la problématique relationnelle 
aurait dû preceder la problématique morpho-fonctionnelle, ele auraît dû se situer en amont. La géographie humaine s'est constituée, entre autres, sur le principe de différentiation spatiale à partir duquel certains tentent aujourd'hui de construire une axiomatique. (RAFFESTIN, 1980, p. 23)

Na medida em que se considera o espaço como produto de uma complexidade de inter-relações entre territórios e territorialidades em permanente movimento histórico, esta problemática aproximanos de um dos fundamentos do paradigma da complexidade, o qual, segundo Morin (2011), considera que o conhecimento só pode ser socialmente pertinente quando situa seu objeto no contexto e no sistema global do qual faz parte, criando estratégias capazes de separar e religar, analisar e sintetizar, abstrair e rearticular os elementos do concreto em seu movimento permanente em algum sentido.

Além disto, ressalta-se que o mesmo autor indagou em que medida o paradigma da complexidade pode ser interessante para explicar concepções e ideologias estabelecidas em torno da ideia de progresso, as quais às vezes possuem, segundo nossa visão, aspectos prejudiciais à manutenção do equilíbrio das relações de poder entre sociedade e espaço.

Isso acontece quando a ideia de progresso (propiciado, no caso ora em epígrafe, pelo crescimento econômico, pela urbanização, pela verticalização, pela produção de centros comerciais, empresariais voltados unicamente para a acumulação de capital, tudo isso norteado pelo CFICF) é reapresentada como uma fábula para mascarar a perversidade da lógica inerente à racionalidade instrumental neoliberal do capitalismo.

Complexidade significa que a ideia de progresso, aqui empregada, comporta incerteza, comporta sua negação e sua degradação potencial e, ao mesmo tempo, a luta contra essa degradação. Em outras palavras, há que fazer um progresso na ideia de progresso, que deve deixar de ser noção linear, simples, segura e irreversível para tornar-se complexa e problemática. (MORIN, 2000, pp. 97-98)

Quanto à estrutura de organização deste artigo apresentar-se-á a natureza do processo de produção do espaço urbano em Recife; discutir-se-á o processo atual dos movimentos sociais como práticas de conquista do espaço urbano também pelas classes subalternas e oprimidas; colocar-se-á o caso do Coque como um território ameaçado pelos interesses especulativos; e indagar-se-á em que medida as Zeis constituíram efetivamente uma conquista social para as classes subalternas e oprimidas ou se são um mecanismo "disfarçado" das classes hegemônicas para deixar os territóriosZeis como reserva de terrenos para serem usados em momentos propícios, fazendo valer os interesses voltados, sobretudo, para a acumulação de capital.

\section{A URBANIZAÇÃO EM RECIFE: SEU PROCESSO E SUA NATUREZA}

Como Recife é uma cidade cujo espaço, desde o início da sua formação histórica, norteou-se pelo capitalismo, de onde exportavam as commodities (cana-de-açúcar, algodão, etc.) para o mercado internacional, o seu espaço foi produzido de acordo com a lógica da racionalidade técnico- 
instrumental deste sistema de produção. Por isto, é preciso, primeiramente, considerar que a natureza do processo de produção do espaço geográfico no Brasil reside, mormente, na primazia, segundo Castilho (2011), dos interesses econômicos voltados, sobretudo, para a acumulação de capital através da criação permanente de valores econômicos - em detrimento dos interesses voltados à realização plena da vida humana.

Em sendo assim, este fato acha-se perfeitamente de acordo com a natureza da formação histórico-territorial do Brasil desde a sua colonização, reforçando, segundo palavras de uma liderança do movimento social Coque (R)Existe, a permanência de uma "lógica predatória de construção das cidades brasileiras".

Esta lógica acontece com base e norteada pela fábula do progresso a qual promete o desenvolvimento urbano para todos e todas, muito embora somente as pessoas que possuem as condições materiais adequadas à sua inserção no mercado sejam de fato as que conseguem obter as vantagens econômicas almejadas.

Desde o início da sua formação territorial, as classes dirigentes em Recife têm ocupado os melhores terrenos do seu espaço. Melhores terrenos em cidades de economia voltada para o exterior com sítio urbano litorâneo, de baixa altitude e sujeito a alagamentos constantes significaram, em princípio, aqueles de terra firme e de fácil acesso ao Porto e/ou às suas adjacências.

Após a ocupação dos referidos terrenos, produzindo seus territórios segundo os interesses do CFICF, as classes dirigentes locais passaram a cobiçar outros terrenos da cidade, ou seja, aqueles que, antes por elas mesmas preteridos, foram-se valorizando. E não se pode deixar de admitir que as próprias classes sociais subalternas e oprimidas contribuíram para a valorização destes terrenos na medida em que os ocupavam e os aterravam a fim de produzirem os seus territórios de existência em Recife, tal como aconteceu em outras cidades brasileiras.

Como vem ocorrendo em todo o mundo capitalista, as classes dirigentes, sempre, buscam expandir seus espaços de ação, visando ampliarem suas possibilidades de gerar riquezas e, progressivamente, consolidando o processo permanente de produção dos seus territórios. Mas esta expansão vem acontecendo, vez por outra, sob os parâmetros de práticas urbanísticas contínuas baseadas no higienismo, através das quais procuraram apropriar-se também dos terrenos aterrados pelas classes subalternas e oprimidas, expulsando-as e, portanto, tentando apagar suas territorialidades.

Compreende-se, assim, que o higienismo, ao nível do discurso dos governos como promotores do progresso, procurou combater situações de insalubridade presentes no espaço urbano, ultrapassando o âmbito das ações profiláticas e imediatistas. Nesse caso, a insalubridade da cidade significava a presença da pobreza e de tudo o mais que possa dificultar a realização dos grandes projetos concretizadores da urbanização capitalista. 0 seu objetivo maior é 
[...] limpar a cidade [...] como a expulsão dos mendigos das pontes e do centro da cidade, a perseguição aos pequenos comerciantes de rua, os protestos contra a degenerescência da moral promovida pelas prostitutas e pelos bandos de desordenados. [...] Outro importante eixo de intervenção dos médicos-higienistas consistiu na morada do pobre, do operário, do vagabundo, ou mesmo a casa operária passaram a ser objeto de controle, a sofrer regulações, perseguições, notificações e de campanhas na imprensa. (MOREIRA, 1992, p. 197)

Na realidade, o higienismo consiste num instrumento de ações implementadas para tornar a cidade mais fluida, fazendo valer os interesses essenciais da urbanização capitalista, liberando os obstáculos à expansão dos interesses do CFICF. E alguns dos maiores obstáculos à realização de tais interesses têm sido a presença das pessoas pertencentes às classes sociais indesejadas (os pobres) e as suas diversas formas de habitar e viver na cidade (favelas, palafitas, prática de atividades do circuito inferior da economia urbana).

Fazendo parte da história urbana da cidade capitalista no âmbito da modernidade, em Recife, o higienismo teve seu início ainda na segunda metade do século XVII, quando o interventor português Marquês de Montebello havia implementado uma série de ações visando retirar pessoas, para a sua administração, indesejadas de áreas da cidade que se valorizavam no curso do processo de urbanização local, visando promover a "limpeza" destas áreas.

Esse urbanismo, no começo do século passado, teve a área do Porto do Recife, tal como ocorreu em outras cidades portuárias brasileiras, como local primordial do seu acontecer histórico. Desta vez com o suporte de ações inspiradas em lições do Barão de Haussmann, visando reforçar a funcionalidade e modernização da área portuária, bem como a reprodução de um espaço que representasse os ideais das classes dirigentes locais que desejavam fazer da sua uma "cidade europeia" a exemplo de uma "Paris tropical".

Tais práticas de urbanismo foram, na verdade, imposição do que acontecia nas cidades dos países centrais do capitalismo à época. Neste sentido, Harvey (2015, p. 346) argumentou que, como "capital da modernidade", Paris tornou-se o modelo a ser seguido na medida em que conseguiu reverter o seu quadro de "cidade doente" através de um conjunto de medidas profiláticas que tiveram como principal sentido extirpar da cidade o que não interessava à permanente geração de valores econômicos, visando reforçar os espaços urbanos como lócus do sistema.

'Ciência higiênica' e 'cirurgia' eram metáforas poderosas e atrativas. Ao abordar as funções metabólicas da cidade - a circulação de ar, água, esgoto - Haussmann tinha como estratégia representacional torná-la um corpo vivo cujas funções vitais precisavam ser purificadas. [...] Mas Haussmann costumava vê-la de maneira fria, como um artefato que podia ser entendido e moldado segundo princípios e técnicas mecânicos e científico-naturais. 
Desse modo, criava-se, através do uso de metáforas inerentes à medicina ${ }^{6}$, ambientes urbanos que, liberados das suas rugosidades históricas, tornaram-se espaços propícios, preponderantemente, para o engendramento das condições necessárias à geração de riquezas. Como exemplos em Recife, teve-se os casos das avenidas Marquês de Olinda, Rio Branco e Alfredo Lisboa, localizadas no bairro histórico conhecido hoje como Recife.

Entre o final dos anos trinta e início dos quarenta, o urbanismo higienista foi ampliado na cidade, sob a batuta do então interventor Agamenon Magalhães. Isso aconteceu por meio das ações de erradicação dos mocambos7, para o que se havia instituído a Liga Social Contra os Mocambos. A Avenida Agamenon Magalhães, outro eixo viário criado após a erradicação dos mocambos que ali se encontravam, dá acesso ao território Coque, articulando este território à primeira perimetral da cidade.

Posteriormente, durante os anos quarenta e setenta também do século passado, outras experiências pontuais foram realizadas na área central histórica da cidade, abrindo largas avenidas e destruindo territórios ocupados, principalmente, pelas classes subalternas. As avenidas Guararapes e Dantas Barreto são, respectivamente, dois exemplos que aconteceram neste período.

A observação do acontecer histórico da urbanização no tempo presente tem-nos mostrado que o anteriormente referido em termos do pensar e agir no espaço urbano está retornando de maneira cada vez mais intensa e célere, aproveitando-se, inclusive, de eventos como o da Copa do Mundo de Futebol 2014; assim como sempre se aproveitaram, também, de eventos naturais (cheias, deslizamentos, etc.) e do apelo à desapropriação de áreas por "utilidade pública" (a construção, por exemplo, de estradas e outras obras públicas).

A realização do processo de acumulação capitalista a todo custo, sempre representou de fato a natureza do processo de urbanização no Brasil. Tanto é que, até o começo dos anos oitenta do século $\mathrm{XX}$, as classes subalternas não tinham direito legal de permanecerem nos seus territórios historicamente construídos no curso da sua existência na cidade. Por outro lado, como o processo de produção capitalista do espaço urbano é contraditório e conflituoso, ele sempre traz em si suas próprias condições para a mudança.

'Os trabalhadores começam a sentir que eles constituem uma classe na sua totalidade; eles tomam consciência de que, se isoladamente são fracos, representam todos juntos uma força; [...] a consciência que eles têm de serem oprimidos se lhes impõe; os trabalhadores adquirem assim uma importância social e política. As grandes cidades são a sede do movimento operário; é aí que os operários começam a refletir sobre sua situação e a sua luta; é aí que se manifesta primeiro a oposição entre proletariado e burguesia'... (LEFEBVRE, 1999b, p. 27)

\footnotetext{
${ }^{6}$ Em um dos seus tantos trabalhos que também se tornou referência entre nós, o qual nos auxilia a entender o processo histórico em que surgiu esta experiência, Foucault (2015) refletiu acerca do papel do olhar clínico no processo de observação e tratamento da realidade social.

${ }^{7}$ Mocambo refere-se a um tipo de habitação popular construída com materiais rústicos pelos próprios moradores.
} 
A percepção coletiva deste processo varia segundo especificidades históricas inerentes a cada território vivido. Contudo, mesmo não se tratando de um movimento operário baseado na concepção simplista de luta de classes entre burguesia e proletariado, a experiência tomada como exemplo neste texto refere-se a um dos movimentos sociais urbanos que, organizando-se com base no território Coque, tem buscado a conquista dos direitos sociais "prometidos pela modernidade", mas que não foram cumpridos até o presente momento.

\begin{abstract}
Se é necessário hoje retomar e ampliar o pensamento dos grandes utopistas [...], não é porque eles sonharam o impossível, é porque esta sociedade traz ainda e sempre, nela, sua utopia: a possível/impossível, o possível que ela torna impossível, últimas contradições, geradoras de situações revolucionárias que coincidem mais com aquelas que anunciou Marx; tanto que não é mais suficiente para resolvê-las, um crescimento organizado (planejado) das forças produtivas! (LEFEBVRE, 1999b, p. 180)
\end{abstract}

Não se conhece outra forma de reação contra a lógica da racionalidade técnico-instrumental capitalista que não seja através do papel e da força dos movimentos sociais, e movidos por uma racionalidade diferente da predominante. De acordo com Santos (1997, p. 246)

\begin{abstract}
Ante a racionalidade dominante, desejosa de tudo conquistar, pode-se, de um ponto de vista dos atores não beneficiados, falar de irracionalidade, isto é, de produção deliberada de situações não-razoáveis. Objetivamente, pode-se dizer também que, a partir dessa racionalidade hegemônica, instalam-se, paralelamente contraracionalidades [as quais] se localizam, de um ponto de vista social, entre os pobres, os migrantes, os excluídos, as minorias...
\end{abstract}

Portanto, é no território de existência das pessoas que estas contra-racionalidades acontecem, favorecendo o acontecer histórico das práticas de movimentos sociais capazes de, efetivamente, conquistar direitos no sentido de, também, produzirem espaços urbanos em que justiça social e qualidade de vida constituam valores de todas e todos, concretizando suas possibilidades de ser mais no espaço urbano.

\title{
4. PROCESSO DE CONQUISTA DO DIREITO AO TERRITÓRIO
}

Antes de tudo, faz-se necessário, portanto, buscar o acesso ao conjunto dos direitos fundamentais a fim de garantir a vida na cidade (HARVEY, 2004), o que, na visão das classes dirigentes constitui prática irracional; mas que, para os movimentos sociais, constitui táticas ou mesmo estratégias contra-racionais, ou seja, ações de reação, e em certa medida, de combate aos imperativos da racionalidade técnico-instrumental capitalista.

É por essa razão que diversos moradores pertencentes às classes subalternas e oprimidas, nas cidades brasileiras, organizam-se e mobilizam-se para mudar suas condições precárias de existência. 0 que pode ser viabilizado, como já dito em outros trabalhos, a partir da construção da cidade na perspectiva da produção do espaço do cidadão. Nesta perspectiva, 
Cada homem vale pelo lugar onde está: o seu valor como produtor, consumidor, cidadão, depende de sua localização no território. [...] Pessoas com as mesmas virtualidades, a mesma formação, até mesmo o mesmo salário têm valor diferente segundo o lugar em que vivem: as oportunidades não são as mesmas. Por isso, a possibilidade de ser mais ou menos cidadão depende, em larga proporção, do ponto do território onde se está. Enquanto um lugar vem a ser condição da sua pobreza, um outro lugar poderia, no mesmo momento histórico, facilitar o acesso àqueles bens e serviços que lhes são teoricamente devidos, mas que, de fato, lhe faltam. (SANTOS, 1987, p. 81, itálicos no original)

Sabe-se que o processo de tomada de consciência acerca da necessidade de lutar para ser mais, da parte dos militantes dos movimentos sociais urbanos, foi o principal motivo que levou as pessoas pertencentes às classes subalternas e oprimidas a buscarem prover seus territórios, na perspectiva do direito ao entorno (SANTOS, 1987), com o conjunto dos bens e serviços fundamentais à completude da sua cidadania: pavimentação e drenagem, saúde, educação, áreas de lazer, etc.

A conquista do conjunto de bens e serviços sociais aconteceu, notadamente, em função do fato de que os movimentos sociais saíram do seu estado de latência, ganhando visibilidade no cenário urbano. 0 que ocorreu a partir do final dos anos setenta com a distensão e abertura política do período da ditadura militar, bem como no início dos oitenta com o processo da transição democrática. Com isso, as classes subalternas e oprimidas foram, paulatinamente, reconquistando seus direitos, reforçando o Movimento Nacional pela Reforma Urbana (MNRU) em seu processo permanente de evolução.

Desse modo, o MNRU, que teve início nos anos cinquenta e sessenta do século XX, alicerçava-se em princípios de democratização da gestão da cidade com a criação de canais de participação, voltando-se notadamente para a defesa do redirecionamento das políticas públicas para as populações historicamente mais espoliadas socioeconomicamente, ressaltando a importância da função social da propriedade da terra. Tratava-se, enfim, do esboço do que se passou a defender, posteriormente, de maneira mais incisiva, como direito à moradia na cidade, passo importante visando à conquista do direito à cidade para todos e todas as pessoas.

No âmbito das conquistas sociais mais relevantes, pode-se citar as seguintes: inclusão das Zeis na Lei de Uso e Ocupação do Solo de 1983; institucionalização do Prezeis, que se ocuparia da regularização da posse dos terrenos e dos processos de urbanização das áreas Zeis; inclusão de dois artigos - 182 e 183 - na Constituição da República Federativa do Brasil (CRFB) promulgada em 1988, que regulamentaram as experiências anteriores dos movimentos sociais em Recife; e maior influência da sociedade nos processos da gestão urbana.

Com esse conjunto de instrumentos legais e urbanísticos socialmente conquistados e implementados, não se poderia mais, pelo menos em termos de princípios, expulsar os moradores das classes sociais subalternas e oprimidas dos seus territórios historicamente produzidos, tal como se fazia antes. 
Mesmo que grande parte dos moradores estivessem em áreas de Zeis (Fig. 2) localizadas em terrenos muito valorizados pela dinâmica territorial urbana capitalista. Com efeito, hoje em dia, muitas Zeis acham-se localizadas em terrenos bastante cobiçados pelo CFICF vinculados aos interesses das classes dirigentes em Recife.

Figura 2. Distribuição Espacial das ZEIS no Município do Recife/Brasil.

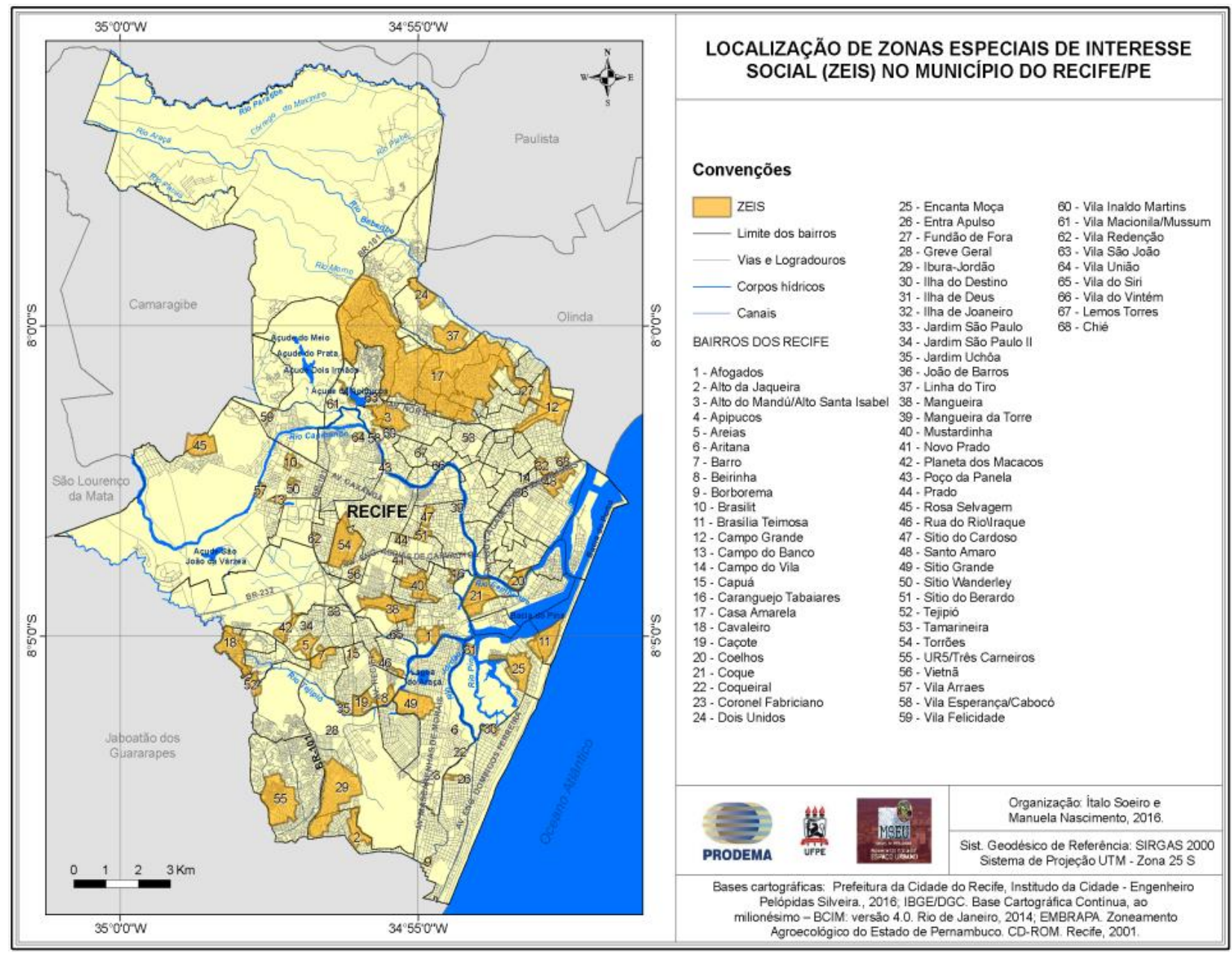

Organização: Manuela Nascimento.

Nota: cada um dos polígonos que representa uma Zeis acha-se localizado em meio a extensas áreas pobres que nunca deixaram de fazer parte da estrutura urbana da cidade.

Posteriormente, em 2001, instituiu-se, através da Lei Federal no 10.257/01, o Estatuto da Cidade (EC), que regulamentou os artigos 182 e 183 da CRFB, reforçando o estabelecimento de mecanismos para a constituição do espaço do cidadão, condição fundamental para que as pessoas possam atingir o direito à cidade. Com o EC, ter-se-ia que reforçar a gestão democrática, a função social da propriedade e o direito à moradia, garantindo: urbanização e legalização dos assentamentos; combate à especulação imobiliária; distribuição mais justa dos serviços públicos no espaço urbano; soluções planejadas e articuladas para os problemas da cidade; a participação da população na formulação e execução das políticas públicas tal como consta do Estatuto da Cidade instituído no ano de 2001. 
Por outro lado, na medida em que, na prática, esse avanço institucional não se concretizou tal como se deveria no âmbito do vivido, tais conquistas representaram concessões para as classes subalternas e oprimidas, com o propósito de manter a lógica dominante da gigantesca operação relativa ao processo de produção do espaço urbano, calcando-se na urbanização capitalista norteada pela lógica da racionalidade técnico-instrumental capitalista neoliberal.

o urbanismo encobre essa gigantesca operação. Ele dissimula seus traços fundamentais, seu sentido e finalidade. Ele oculta, sob aparência positiva, humanista, tecnológica, a estratégia capitalista: o domínio do espaço, a luta contra a queda tendencial do lucro médio etc. Essa estratégia oprime o 'usuário', o 'participante', o simples 'habitante'. (LEFEBVRE, 1999b, p.143)

Entretanto, em outras palavras, mais cedo ou mais tarde, pouco a pouco, os discursos do progresso escamoteado pela promessa do desenvolvimento urbano, da legislação urbanística e outros são percebidos pelos "homens simples" como fábulas; motivo pelo qual se articulam e, por conseguinte, se remobilizam com a finalidade retomarem a continuidade da luta pelo espaço do cidadão e, consequentemente, pelo "direito à cidade" para todos e todas as pessoas.

Enfim, durante o processo de história urbana em Recife, muitos espaços foram conquistados tornando-se territórios de parte significativa das classes subalternas e oprimidas e, mesmo, reconhecidos pela legislação local (Zeis), instrumentos urbanísticos (Prezeis) foram instituídos através dos quais a sociedade começou a buscar interferir em decisões atinentes à sua existência na cidade; porém, ainda se está muito longe da conquista efetiva do direito acima referido.

\section{AMEAÇAS AO TERRITÓRIO COQUE}

Convém, antes de tudo, lembrar que, conforme argumentação de Harvey (2010), a continuidade do processo de expansão e reprodução do espaço urbano também faz parte da lógica do sistema capitalista, o qual utiliza diversos territórios das cidades como instrumentos de extração da mais-valia visando à permanente geração de valores.

Neste sentido, principalmente no curso dos anos recentes, os grandes projetos de caráter urbanístico-empresarial vêm sendo utilizados como instrumentos de aceleração da urbanização neoliberal a exemplo do que vem ocorrendo tanto em Recife, como em várias outras cidades do mundo. Tais

[...] projetos específicos a um determinado lugar também têm o hábito de se tornarem de atenção pública e política desviando a atenção e até recursos dos problemas mais amplos [...]. Normalmente o novo empreendedorismo urbano se apóia na parceria público-privada, enfocando o investimento e o desenvolvimento econômico, por meio da construção especulativa do lugar em vez da melhoria das condições num território específico, enquanto seu objetivo econômico imediato... (HARVEY, 2005, 174) 
Com efeito, os grandes projetos urbanísticos desconsideram os territórios e as territorialidades das classes subalternas e oprimidas, desterritorializando-as e, por conseguinte, enfraquecendo-as, pois quando as pessoas são retiradas dos seus territórios elas perdem parte das suas vidas. Porém, os moradores e as moradoras do Coque nunca deixaram de resistir contra a sua desterritorialização, mesmo diante das fortes adversidades inerentes aos imperativos da lógica da racionalidade técnicoinstrumental capitalista.

A situação acima colocada representa muito bem o que vem ocorrendo, atualmente, em áreas da Zeis Coque, como nas de outros territórios historicamente produzidos em Recife. Para esta área, estava prevista a execução de grandes projetos urbanísticos dentre os quais se destacam os seguintes: ampliação do sistema viário, viabilização da mobilidade rápida do transporte público, retificação do Canal Ibiporã e urbanização das suas margens, bem como a construção de um polo jurídico (Fig. 3). E isto somente para mencionar alguns

Figura 3. Intervenções urbanísticas previstas na Zeis Coque.

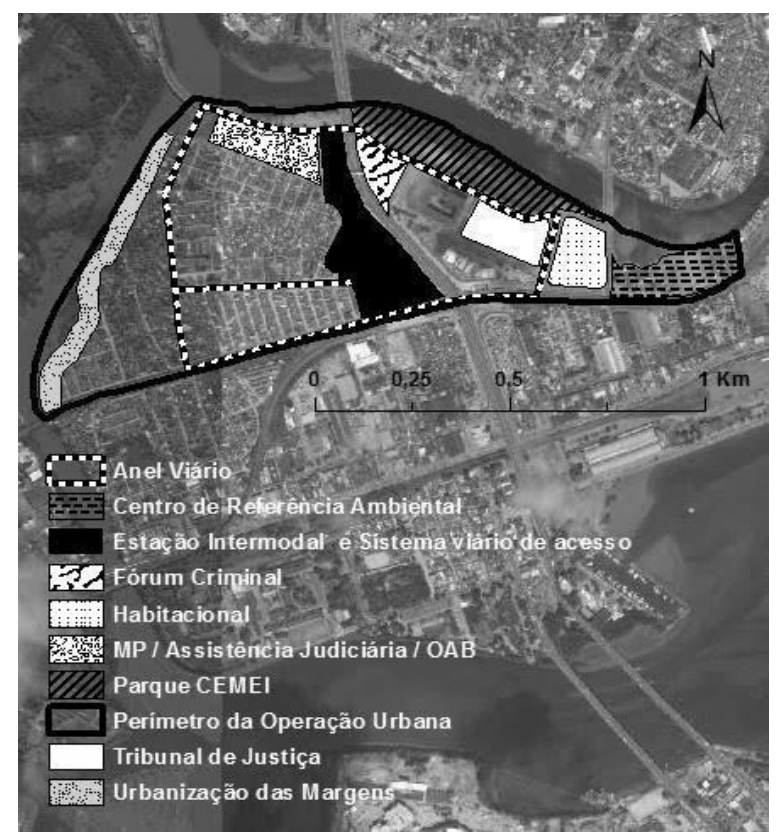

Fonte: Direitos Urbano, 2013. Trabalhado por Katielle Susanne, pesquisadora do MSEU Nota: a execução de algumas dessas obras foi revista, pelos poderes públicos instituídos, em função de pressão dos moradores locais, que se opuseram contra o processo de remoção que vem ocorrendo, há décadas, também naquele território.

A leitura do documento intitulado Coque Vive (2008) demonstra que se tem visto, durante mais de cinquenta anos, que este território perdeu cerca de $51 \%$ da sua área, processo que vem acontecendo de maneira paulatina e sutil; mas que está perfeitamente de acordo com a lógica do processo de produção puramente econômica do espaço urbano.

De acordo com a visão de militantes do Movimento Coque (R)Existe: em 1975, foi executado um projeto de readequação urbanística na área, visando evitar as frequentes cheias do rio, o que removeu 
muitas famílias para bairros distantes como Ibura e Jordão (Recife) e Janga (Paulista); em 1980, as obras do metrô expulsaram cerca de setecentas famílias da área; em 1985, construiu-se o Fórum Rodolfo Aureliano em terreno da área, dando início ao que hoje se está chamando de um futuro polo jurídico; e em 2012, ocorreu o alargamento da Estação Joana Bezerra e do viaduto Capitão Temudo, que passa pelas suas proximidades. A propósito, o território Coque acha-se localizado num dos mais importantes nós da malha viária da cidade de Recife.

Neste mesmo ano, moradores do Canal Ibiporã, o qual se situa no interior do território, receberam, sob o que se pode chamar de "pressão psicológica", ordens de despejo em troca de indenizações irrisórias, ferindo o seu direito à moradia e passando por cima de leis e decisões públicas tomadas anteriormente. A este respeito, ressalta-se que, segundo os moradores, a Prefeitura do Recife já havia aprovado, no Orçamento Participativo (OP) de 2002, a pavimentação e drenagem da rua que margeia o referido canal, bem como a construção de um Conjunto Habitacional para as famílias que estavam vivendo praticamente em cima do canal sob as condições mais precárias de insalubridade. Porém, a atual gestão urbana do Recife não considerou essas conquistas quando encaminhou as ordens de despejo que fez com que os moradores em questão procurassem alternativas de não deixar aquele território, reestabelecendo-se em palafitas levantadas às margens do rio pelos próprios moradores locais.

Constatou-se que essa postura governamental vem acontecendo em todas as grandes cidades brasileiras - São Paulo, Rio de Janeiro, Belo Horizonte, Salvador, Porto Alegre, Fortaleza, etc. - e constituem um conjunto de ações fragmentadas e desarticuladas umas das outras. Por outro lado, elas constituem um conjunto de ações que obedecem à lógica única dos interesses especulativos alienantes e, portanto, alheios às pessoas do território, desrespeitando-as. E isso, através de posturas, novamente, profiláticas visando extirpar as pessoas dos seus territórios sem considerá-las como partes da cidade.

Uma parte considerável dos moradores e das moradoras do Coque têm conseguido manter certa unidade em termos de interesses comuns, apesar das adversidades enfrentadas para conseguirem mobilizar mais pessoas, conseguindo reunir-se para participarem das assembleias e dos protestos contra a postura de governo urbano.

Os moradores e as moradoras conseguiam realizar assembleias para discutir as ameaças externas pela implementação dos grandes projetos "empresariais" para o Coque, assim como estratégias coletivas para responderem às ameaças ao seu território. Das assembleias participam, numa perspectiva de rede social, pessoal de universidades, Organizações não Governamentais (ONG), etc., reforçando a luta social no/e a partir do Coque.

De acordo com o caso específico ora abordado, que foi experienciado pelo MSEU, os movimentos sociais, como os que ocorrem no e a partir do Coque (R)Existe, buscam, também através do uso de novas tecnologias informacionais, atualizar suas táticas - e estratégias! - de mobilização, mantendo 
seu papel, segundo Castells (2013), de produtores de novos valores, construindo outras alternativas de espaço público e criando comunidades livres no espaço. Desse modo, vale a pena ressaltar, ainda, que, seguindo parâmetros atuais dos movimentos sociais no mundo, mas ao mesmo tempo mantendo especificidades territoriais locais, os movimentos sociais urbanos no Brasil continuam possuindo como

[...] verdadeiro objetivo [...] aumentar a consciência dos cidadãos em geral, qualificá-los pela participação nos próprios movimentos e num amplo processo de deliberação sobre suas vidas e seu país, e confiar em sua capacidade de tomar suas próprias decisões em relação à classe política. [...] A derradeira batalha pela mudança social é decidida na mente das pessoas, e nesse sentido os movimentos sociais em rede têm feito grande progresso no plano internacional. (CASTELLS, 2013, p. 173)

Durante a realização das suas assembleias, eram reforçadas as experiências dos movimentos sociais na cidade e, em particular, no Coque. Isso no sentido de mantê-los unidos e mobilizados até conseguirem fazer valer seus interesses e valores, mostrando que eles possuem um "lugar forte". A este respeito, ressalta-se que, para Santos (1997, p. 256), engendrando-se da proximidade geográfica como contiguidade física entre pessoas capazes de criar solidariedades, laços culturais e identidade, fortalecendo os lugares. Neste sentido lugar forte representa

[...] um cotidiano compartido entre as mais diversas pessoas, firmas e instituições cooperação e conflito são a base da vida em comum. [...] O lugar é o quadro de referência pragmática ao mundo, do qual the vêm solicitações e ordens precisas de ações condicionadas, mas é também o teatro insubstituível das paixões humanas, responsáveis, através da ação comunicativa, pelas mais diversas manifestações da espontaneidade e da criatividade.

Esta criatividade, por outro lado, só pode ser aflorada com base na escala local, visto que é neste nível do cotidiano que se acham os territórios/territorialidades das classes sociais subalternas e oprimidas, as quais, justamente, constituem aquelas que criticam e se mobilizam contra o processo homogeneizador dos interesses globais do sistema capitalista.

É justamente aí onde estão os pobres, os quais, se de um lado constituem, pela sua própria presença no espaço urbano brasileiro, “obstáculo à difusão dos capitais novos” (SANTOS, 1997, p. 259); de outro, é notório que a sua presença no espaço como populações territorializadas

[...] aumenta e enriquece a diversidade socioespacial, que tanto se manifesta pela produção da materialidade em bairros e sítios tão contrastantes, quanto pelas formas de trabalho e de vida. Com isso, aliás, tanto se ampliam a necessidade e as formas da divisão do trabalho, como as possibilidades e as vias da intersubjetividade e da interação. É por aí que a cidade encontra o seu caminho para o futuro.

Durante o curso dos anos 1980 que, saindo novamente do seu estado de latência, os movimentos sociais com base em suas especificidades territoriais locais - em torno do Coque - voltaram a impedir a realização de dois projetos ligados aos interesses vinculados à racionalidade técnico-instrumental do capitalismo neoliberal na busca de ampliar o espaço voltado preponderantemente à geração de valores econômicos: o da instalação de um estacionamento de grande dimensão para evitar que os 
automóveis particulares se dirigissem até à área central histórica da cidade; e o da construção de um shopping Center.

Mesmo que as propostas de tais projetos tenham chegado até os moradores do Coque, mascaradas pelas conhecidas fábulas do progresso baseadas em promessas de geração de empregos e rendas para eles, as obras não foram executadas. Isso, sobretudo, porque naquele momento a maior parte dos moradores do Coque percebeu que a garantia do seu território era muito mais importante do que uma fábula débil e incerta.

No entanto, vale ressaltar que, mesmo tendo que recuarem em algum momento no tempo, as classes dirigentes nunca desistem e sempre retornam com as mesmas propostas, mascaradas de novas propostas, envoltas na fábula do progresso/desenvolvimento, até conseguirem saciar sua permanente sede de expansão territorial. É o que acontece ainda hoje, visto que o seu projeto de cidade continua o mesmo, isto é, calcando-se no higienismo funcional de outrora, e o pior, facilitado pelo Estado, que deveria primar pelo Bem Comum.

Portanto, ressalta-se que, em 2010, formalizou-se uma proposta de instalação de um Polo Jurídico na Ilha Joana Bezerra, incluindo o território Coque, cuja intencionalidade continuou sendo a "limpeza" da área com a retirada das territorialidades historicamente construídas pelos moradores pobres locais.

Disso, estabeleceu-se o projeto de Lei no 17645/10 de iniciativa da Prefeitura do Recife, segundo o qual se aprovaria o plano da Operação Urbana Consorciada Joana Bezerra, com o que se autorizaria ações de desapropriação, desafetação de vias públicas no perímetro de intervenção, definição de novos parâmetros construtivos permitindo a verticalização na área, etc. Só que, novamente, o movimento social local - desta vez liderado pelo ativismo do Coque (R)Existe - conseguiu mobilizar-se - fazendo muito barulho - a fim de intervir nos planos da referida Operação, impondo novos contornos e arranjos ao processo de produção do espaço urbano na cidade de Recife.

No curso do ano de 2013, o mesmo movimento conseguiu impedir a construção da sede da Ordem dos Advogados do Brasil (OAB) e do Ministério Público (MP), duas obras que reforçariam a intenção, da parte dos interesses hegemônicos, da implantação do já citado Polo Jurídico na área. Isso notadamente porque, em vez da geração de empregos e rendas, os moradores do Coque perceberam que haveria mais desapropriações e, consequentemente, perda de mais porções do seu território para os interesses especulativos hegemônicos que se fazem presentes em Recife.

Os movimentos sociais urbanos, na realidade, não se opõem aos processos de organização espacial baseada na instalação dos chamados Polos Terciários (Jurídico, Médico-hospitalar, etc.) em si, uma vez que seus participantes sabem que tais empreendimentos possuem sim capacidade para gerar empregos e rendas, inserindo mais pessoas nos mercados de trabalho e consumo. Mas, com toda razão, eles atuam contra o significado de mais esta técnica de organização espacial para seus territórios, 
entrevendo que eles perdem muito mais permitindo a concretização do referido projeto com base em sua remoção para outras áreas da cidade e sem terem garantias concretas para a sua inclusão social.

Portanto, tem havido uma série de movimentos de oposição contra a retirada, sem diálogo, das famílias que moravam às margens de trechos do Canal Ibiporã, tanto que, segundo lideranças locais do movimento Coque (R)Existe, as indenizações tiveram aumentos significativos. Em meados de 2015, contudo, a construção do referido canal saiu do papel.

Tem-se visto que, no momento em que moradores e moradoras do Coque - como de qualquer outro território ameaçado da cidade - percebem que a lógica hegemônica vigente de produção do espaço urbano ameaça o seu território, eles, também, retomam seus processos de organização e mobilização para resistirem, fortalecendo-se enquanto movimento social.

[...] a cidade grande é o espaço onde os fracos podem subsistir. [...] E nesta, o próprio meio ambiente construído frequentemente constitui um obstáculo à difusão dos capitais novos. [...] Palco da atividade de todos os capitais e de todos os trabalhos, ela pode atrair e acolher as multidões de pobres expulsos do campo e das cidades médias [...]. E a presença dos pobres aumenta e enriquece a diversidade socioespacial, que tanto se manifesta pela produção da materialidade em bairros e sítios tão contrastantes, quanto pelas formas de trabalho e de vida. [...] É por aí que a cidade encontra o seu caminho para o futuro. (SANTOS, 1997, pp. 258-59)

Enfim, os moradores e as moradoras do Coque buscam encontrar esse caminho com sua arma mais forte, isto é, a (r)existência no lugar. Sobretudo, quando percebem que não fazem parte do propósito global do atual projeto de cidade vigente em Recife.

Todavia, o que mais nos intriga é que o Coque, como se viu, é uma Zeis, isto é, um território cuja posse da terra já deveria ter sido legalizada há décadas, e, consequentemente, toda a sua área já deveria ter sido urbanizada. E não se pode dizer que os moradores e as moradoras do lugar não se mobilizaram para reivindicarem os seus direitos.

Mas por que razão a completude desse conjunto de conquistas, essenciais à vida dos pobres com dignidade na cidade, não aconteceu até o momento atual, a ponto dos moradores e das moradoras ainda se sentirem ameaçados e inseguros diante da permanência de tantas adversidades que lhes acometem cotidianamente?

\section{A ZEIS ENTRE SER UMA CONQUISTA SOCIAL OU UMA RESERVA DE TERRENOS PARA O CAPITAL: A LUTA CONTINUA...}

Antes de tudo, reitera-se que, como todo processo social, a urbanização - higienista gentrificadora - também não acontece igualmente em todos os lugares. Daí por que os embates entre os interesses especulativos do CFICF e os da realização plena da vida humana nas cidades brasileiras e nas de outros países ditos "subdesenvolvidos industrializados", "emergentes', etc. - ainda apresentam fortes dificuldades no que tange à sua superação. 
Por um lado, constatou-se que, como ocorreu em outras cidades do Brasil, a Prefeitura do Recife, em razão das pressões sociais dos moradores e das moradoras do Coque, concedeu o status de Zeis ao seu território; mas por outro, quando não havia resistências fortes, esse espaço foi, progressivamente, perdendo áreas para instituições vinculadas aos interesses inerentes ao CFICF.

O território em epígrafe ainda não se reduziu mais e manteve suas territorialidades históricas, porque algumas vezes o movimento social ultrapassou seu estado de latência, tornando-se visível e ativo, na busca de fazer oposição contra as diversas tentativas externas de ocupação territorial da parte das classes sociais dirigentes que cobiçavam porções da sua área para a fixação dos objetos espaciais garantidores dos seus interesses econômico-financeiros.

Levanta-se, assim, a hipótese de que, talvez, a Zeis tenha funcionado como um instrumento urbanístico estratégico dos poderes hegemônicos para atenuar tensões sociais do ambiente urbano nos anos oitenta do século passado quando os movimentos sociais estavam atuantes, ganhando tempo na medida em que esses territórios ficaram como uma reserva de terras para serem utilizadas em momentos de crescimento econômico como os que têm ocorrido em períodos recentes.

Mas, jamais as classes dirigentes desistem de afastar os pobres do seu caminho, muito embora não tenham contado, tal como ocorrera na transformação de Paris, com o fato de que

[...] embora os pobres não se ressentissem com a riqueza como tal, sua própria condição periclitante, unida à crescente afluência dos ricos, certamente representava uma ameaça à segurança da classe mais abastada. Além disso, essa ameaça tinha uma expressão geopolítica. (HARVEY, 2015, p. 374)

No momento em que se evidencia que muitas Zeis como a do território Coque existem desde 1983 e que ainda apresentam os mesmos problemas que se manifestavam naquele período - em termos da precariedade na infraestrutura urbana, da irregularidade quanto à posse do terreno, das condições precárias de existência, etc. -, não obstante os protestos sociais ocorridos para solucionálos, chega-se à conclusão de que, na verdade, não se desejava completar a promessa da inclusão social dos pobres na cidade.

Desejava-se, ao contrário, como temos reconhecidos em outros escritos, manter a referida área como que em reserva a fim de ser apropriada pelos agentes do CFICF nos momentos pertinentes do processo de valorização econômico-financeira do espaço urbano em Recife.

Diante do que se acabou de argumentar, crê-se que a manutenção do quadro precário de referências em tais territórios e o "esvaziamento" do fórum do Prezeis acontecem como algo de propósito, justamente para desestabilizar o sentimento de pertencimento inerente a todo processo de construção histórica dos territórios vividos. E isto nos tem sido dito diversas vezes pelos próprios moradores e pelas próprias moradoras em conversa informal.

A maioria dos moradores e das moradoras, portanto, sequer sabe o que são Zeis e Prezeis, fato que corrobora a ausência de vínculos entre o povo e estas duas instituições que representam 
resultados efetivos dos movimentos sociais em Recife. Ocorre também, para quem já teve contato com o Prezeis, verdadeira aversão a certas lideranças deste fórum, alegando que as lideranças tornaram-se "pelegas" e passaram a preocuparem-se mais com seus projetos individuais do que com os projetos coletivos inerentes ao território.

Do ponto de vista da localização geográfica, o Coque está rodeado por espaços cujo metro quadrado é dos mais caros em Recife, tais como os bairros Ilha do Leite e Ilha Joana Bezerra. Portanto, o conjunto de problemas acima exposto deixou tais territórios em uma situação de insegurança e vulnerabilidade com relação aos imperativos dos interesses do CFICF. Com efeito, atualmente, muitos desses territórios Zeis - não somente o do Coque - têm sido cobiçados pelos interesses imobiliários e financeiros da cidade, principalmente porque o espaço urbano local tornou-se pequeno para tanta cobiça.

Desse modo, por um lado, a Zeis é uma conquista social; mas, por outro, é uma estratégia de reserva de terra para fazer valer os imperativos do CFICF, situando-se no âmbito de um permanente embate entre os interesses da lógica técnico-instrumental do capitalismo neoliberal e a dos interesses da realização plena da vida humana.

Então, faz-se necessário que os territórios das classes subalternas e oprimidas tornem-se lugares efetivamente fortes, para influir na construção de uma gestão urbana capaz de considerar a cidade, em teoria e prática, como uma totalidade complexa para todas e todos. Para o que, aliás, os poderes instituídos devem re-aproximar-se efetivamente das classes subalternas, a fim de que, no curso do tempo, tenha-se condições de contemplar as necessidades e os desejos de todos.

As experiências de movimentos sociais que acontecem, simultaneamente, na escala "do bairro" e "para além do bairro", tal como colocado por Souza (2006), utilizando-se dos novos meios informacionais (internet, facebook, twitter, etc.) e dos meios tradicionais (assembleias, mobilizações no espaço, ocupação de espaços com os próprios corpos, etc.) de mobilização social, tornam-se fundamentais para a construção do espaço do cidadão. 0 que tem fortalecido muito os processos de mobilização, articulação e pressão social sobre os poderes instituídos.

Não se pode negar, portanto, a garantia de avanços significativos em termos de reforço dos valores de solidariedade, autonomia e construção de espaço público. Porém, concomitantemente, há problemas internos à própria lógica de organização e mobilização que impedem que se dê saltos mais significativos no sentido da construção de algo efetivamente diferente, retornando ao impasse histórico dos movimentos sociais no Brasil. 0 que não cabe mais discutir aqui uma vez que já o fizemos em outras ocasiões.

Reforça-se, e qualquer maneira, a necessidade permanente de utilização do conjunto de meios presentes no território em que as pessoas vivem e a partir do qual elas se organizam e se mobilizam, reaproximando-se geograficamente no sentido do fortalecimento do seu lugar; o que nos remete a uma 
perspectiva contínua, no tempo e no espaço, de luta social pela conquista do espaço do cidadão, com a qual as pessoas pobres também poderão ser mais na cidade e, por sua vez, no mundo.

Ademais do que se acabou de colocar, a pluralidade da cidade faz com que existam territórios de fato vividos e que a democracia do espaço se manifeste no direito de morar, de ir e vir, no acesso não só às mínimas condições de vida, mas também à dignidade e com autonomia para construir sua própria história e em conjunto, não permitindo retrocessos no âmbito das suas conquistas.

Com o que se poderá obter a tão sonhada e almejada qualidade de vida e justiça social. Moradores e moradoras pobres dos territórios vividos das cidades, uni-vos!

\section{REFERÊNCIAS}

CASTELLS, Manuel. Redes de indignação e esperança. Movimentos sociais na era da internet. Rio de Janeiro: Zahar, 2013.

CASTILHO, Cláudio Jorge Moura de. Processo de produção desigual do espaço urbano: Recife impasse permanente da coexistência de interesses da "cidade à acumulação de capital" e da "cidade à realização plena da vida humana" Acta Geográfica, Boa Vista, 5,95-113, 2011.

CENDHEC. PREZEIS Plano de regularização das Zonas especiais de interesse social. Manual para lideranças. Recife: Fase/NE, 1997.

COQUE VIVE. Coque vive notícias. Educação para as mídias. Recife: UFPE, 2008.

ESTATUTO DA CIDADE. Conhecendo o Estatuto da Cidade. Fase/Forum Nacional de Reforma Urbana/Caixa Econômica Federal, s/d.

FOUCAULT, Michel. $O$ nascimento da clínica. $7 \underline{\text { a }}$ ed. Rio de Janeiro: Forense Universitária, 2015. (1980, primeira edição)

HARVEY, David. Espaços de esperança. São Paulo: Edições Loyola, 2004.

A produção capitalista do espaço. São Paulo: Annablume, 2005.

. The enigma of capital and the crisis of capitalism. London: Profile books, 2010.

Paris, capital da modernidade. São Paulo: Boitempo, 2015.
MOREIRA, Fernando Diniz. Higienismo enquanto prática urbanística: o exemplo do Recife no início do século. Cadernos de Estudos Sociais, Recife, v.8, n. 2, pp. 185-205, jul./dez, 1992.

LEFEBVRE, Henri. A revolução urbana. Belo Horizonte: Editora da Universidade Federal de Minas Gerais, 1999a.

. A cidade do capital. Rio de Janeiro: DP\&A Editora, 1999b.

MORIN, Edgard. Ciência com consciência. 4aㅡ edição. Rio de Janeiro: Bertrand Brasil, 2000.

La sfida della complexità/Le défi de la complexité. Firenze: Le Lettere, 2011.

PASSET, René. A ilusão neoliberal. Rio de Janeiro:Record, 2002.

RAFFESTIN, Claude. Pour une géographie $d u$ pouvoir. Paris: Litec, 1980.

ROLNIK, Raquel. Guerra dos lugares: a colonização da terra e da moradia na era das finanças. São Paulo: Boitempo, 2015.

SANTOS, Milton. O espaço do cidadão. São Paulo: Nobel, 1987.

. A natureza do espaço. Técnica e tempo. Razão e emoção. São Paulo:Edusp, 1997.

SOUZA, Marcelo Lopes de. A prisão e a ágora. Reflexões em torno da democratização do planejamento e da gestão das cidades. Rio de Janeiro: Bertrand Brasil, 2006. 